Nouveaux visages de l'anglais de spécialité : objectifs, domaines, approches et outils de demain

\title{
Research in electronically-mediated communication in professional contexts - revisiting the past, preparing for the future
}

Julio Gimenez

\section{CpenEdition}

\section{Journals}

Electronic version

URL: http://journals.openedition.org/asp/3094

DOI: 10.4000/asp.3094

ISSN: 2108-6354

\section{Publisher}

Groupe d'étude et de recherche en anglais de spécialité

Printed version

Date of publication: 15 November 2012

Number of pages: $79-88$

ISSN: 1246-8185

\section{Electronic reference}

Julio Gimenez, "Research in electronically-mediated communication in professional contexts revisiting the past, preparing for the future », ASp [Online], 62 | 2012, Online since 07 October 2014, connection on 02 November 2020. URL : http://journals.openedition.org/asp/3094; DOI : https:// doi.org/10.4000/asp.3094

This text was automatically generated on 2 November 2020 .

Tous droits réservés 


\title{
Research in electronically-mediated communication in professional contexts - revisiting the past, preparing for the future
}

\author{
Julio Gimenez
}

\section{Introduction}

1 The past two decades or so have witnessed a considerable increase in our interest in the nature and role of electronic media in professional communication. Since the first attempts to examine electronically-mediated communication (EMC) back in the late 1980 s to recent developments in the field, we have moved from investigating electronic media in themselves to examining how media, context and communicators interact together. This shift in interest has created exciting research and pedagogic opportunities.

2 This paper starts by revisiting the main contributions that developments in the field of EMC since the late 1980s have made to our understanding of the nature and purposes of communication in professional contexts. It looks at the intersection between media and context, media and identity and media and professional language and discourses. The paper then examines the latest advances in EMC. In this respect, it focuses on two recent developments: multicommunication and Enterprise Social Networking (ESN).

In section three, the paper forecasts a number of topics and activities in electronicallymediated communication which will occupy our research time and interest in the coming years, and examines possible connections between these predictions and the four axes discussed at the GERAS 33rd conference: language and discourses, research findings and new didactic applications, culture and technological advances. 


\section{The work of electronically-mediated communication so far}

4 The first studies in electronically-mediated communication (EMC) in general and email communication in particular were interested in looking at EMC from a rather technical perspective in order to establish the communication 'capacity' of the new medium. Daft and Lengel (1986), for instance, proposed their channel capacity hypothesis and compared EMC with face-to-face communication in the business world. They concluded that electronic media were less rich in terms of the communication possibilities they offer, thus determining what media people chose depending on their communicative purposes. Two years later, Lengel and Daft (1988) reported that the executives in their research preferred electronic media for routine communication and face-to-face communication for non-routine tasks.

5 Later studies, however, produced somewhat contradictory results. Markus (1994), for example, found that the managers in her study preferred EMC for routine as well as non-routine communication and that low-channel capacity media (e.g., email) could also be used for complex communication if the corporation encouraged it. Markus's represented one of the first attempts to link EMC with the culture of the corporation where it was used. In a similar vein, Nickerson (1999) found a widespread use of EMC within the Dutch division of the multinational corporation she investigated, concluding that EMC helps a corporation to structure its organisation, and can be deeply embedded in both its communication and organisational practices.

In an attempt to examine the impact of EMC on workplace communication, Gimenez's (2000: 249) research into email communication in national and multinational corporate settings showed how the informal nature of email helped to shape the "discursive practices in the context of interpersonal communication, making it more informal and personalised in many respects". His research also showed that the informal and flexible style of email in professional communication seemed to equate with efficiency, one of the key features that participants in his study frequently mentioned in relation to business communication, thus showing another significant aspect emerging from the interplay between media and context of use.

7 Along similar lines, a number of studies have shown that EMC can also offer a window onto the reality of the corporate world. Research by Akar (2002) in Turkey has demonstrated that EMC can become the mediating factor between national and corporate cultures, and Poncini's (2002) research, which looked at the role of electronic communication in negotiations between Italians and Americans, has skilfully shown how EMC can support identity-building strategies in negotiating instances.

On examining the communication patterns between the European headquarters and the Argentinian subsidiary of a multinational, Gimenez (2002) demonstrated that EMC may provide a clear picture of the lack of convergence between local identities and global decisions which do not always find it easy to co-exist. The local corporate reality and socially-constructed values of the Argentinian subsidiary tended to override most of the globally-adopted conventions to which the head office in Europe wanted the Argentinian agents to adhere and this transpired the mediated communication between the European headquarters and the Argentinian subsidiary. 
9 More recently, Jensen (2009: 16) has shown how interaction goals can actually be reached in negotiations conducted by email despite some theoretical considerations that hold that email is an "information transaction medium, rather than an interaction-based communication system". Jensen's observation exemplifies the theoretical struggles that the field is still showing to sanction email as a legitimate way for doing business. In her research, Jensen managed to identify how the frequency in the use of interactional metadiscourse developed and subsequently converged as the relationship progressed towards a more contextually stable and more personalised level of communication. Similarly, the results of the qualitative analysis of her research showed that discourse markers may perform different functions relative to the context of interaction, highlighting once again the importance of bringing context and culture into the analysis of communication in professional contexts.

Research on EMC has also provided some significant insights into the languages and discourses of professional communication. Recent research by Jensen (2009) has demonstrated how language and interpersonal discourse can be mediated electronically. By examining the different phases of an electronically mediated negotiation, Jensen established that during the 'contact phase' of the negotiation the buyer and the seller focused on cooperation and making their professional relationship come to fruition. They frequently used interactionals, which Jensen defines as markers mainly used to create a relationship with the audience, with the buyer using almost twice as many interactionals as the seller, clearly showing a more marked interest on the part of the buyer and that power lies with the seller. A similar tendency was shown in relation to the use of metadiscursive elements such as boosters, engagement markers and self-mention that the buyer used to establish himself and his company as worthy of negotiating with, whilst the seller responded with a similar use of engagement markers to show his interest in a future business relationship but also to display his control over the situation.

11 In the 'negotiation phase' of the electronically-mediated negotiation, Jensen, however, found that the way the discursive strategies were used in the contact phase were reversed. The buyer signalled strength by taking control of the information flow and a marked decrease in the use of, for example, engagement markers to signal his tactical restriction of interest in products that the seller had to offer. The seller, on the other hand, combined self-mention with attitude markers and boosters to emphasise his appeal to the buyer whilst also increasing his use of engagement and attitude markers, a strategy that was previously associated with the buyer in the contact phase. The use of these discursive strategies by the buyer and seller are shown in Table 1. Jensen's research shows a clear example of how discursive interactions in professional contexts can also be accessed and analysed by means of electronically-mediated communication.

In relation to EMC as a space where language use, communication and media intersect, a number of research studies have started to show emerging patterns which are worthy of consideration. In his work on the language of business emails, Gimenez $(2005,2006)$ managed to identify a few interesting patterns of use of English gradually shifting with new elements being incorporated into the language.

Table 1. Discursive strategies used by the seller and buyer in the contact and negotiation phases

\begin{tabular}{|l|l|l|}
\hline Phase & Buyer & Seller \\
\hline
\end{tabular}




\begin{tabular}{|l|l|l|}
\hline Contact phase & $\begin{array}{l}\text { - Interactionals (23.9\%) } \\
\text { - Boosters, engagement markers } \\
\text { and self-mention = credentials }\end{array}$ & $\begin{array}{l}\text { - Interactionals (17.9\%) } \\
\text { - Engagement markers = interest in business } \\
\text { relationship, whilst displaying control }\end{array}$ \\
\hline $\begin{array}{l}\text { Negotiation } \\
\text { phase }\end{array}$ & $\begin{array}{l}\text { - Control of the information flow } \\
\text { - Decrease in use of engagement } \\
\text { markers = detachment }\end{array}$ & $\begin{array}{l}\text { - Self-mention with attitude markers and } \\
\text { boosters = emphasise his appeal to the buyer } \\
\text { - Increased engagement and attitude markers } \\
\text { show interest in the deal }\end{array}$ \\
\hline
\end{tabular}

(After Jensen 2009)

13 An analysis of the language used in business email communication shows that variation and change in language use have started to occur as a result of two distinctive processes: 'adaptation' and 'creation' which seem indicative of the interaction between individual agency and structural demands of workplace communication. Adaptation is mainly reflected in the flouting of rules and simplification processes. Although emails with no full stops or commas are difficult to read and can even change the meaning of the message, and misspellings and lack of capitalisation may create the wrong impression, rules of capitalisation, punctuation, and spelling can be easily flouted in email communication. Coupled with the flouting of rules, emails show a tendency for normally hyphenated words to lose the hyphen, for example 'email' and 'emailing', a process that usually takes place after hyphenated words have existed in a language and have been widely used for some time although in a few cases, the reverse is also true. Simplification can also be present at the syntactic level where there is a clear tendency to avoid complex structures (e.g., coordination preferred to subordination; elliptical structures; dropping of personal pronouns).

14 As to creation, it is mainly present in two significant creative linguistic processes: abbreviation and the creation of new meanings. Most personal abbreviations are being created especially for internal communication purposes, with some being more obscure (e.g., 'BW' for 'best wishes') than others (e.g., 'rgds' for 'regards'). Similarly, new meanings can be associated with existing words by a change in grammatical category. This creation process is commonly found when nouns are turned into verbs: e.g., 'email' (n) into 'to email', 'cc [carbon copy]' (n) into 'to cc', or used in an adjectival function: e.g., 'email message'. In the case of recent creations there are sometimes two forms co-existing (e.g., 'to cc someone' and 'to copy someone into a message'). Examples of variation and change in business email communication are given in Table 2.

Table 2. Examples of the adaptation and creation in email communication

\begin{tabular}{|l|l|l|}
\hline \multicolumn{1}{|c|}{ Change category } & Adaptation process & Creation process \\
\hline $\begin{array}{l}\text { Capitalisation, punctuation } \\
\text { and spelling }\end{array}$ & $\begin{array}{l}\text { i think our ny office may } \\
\text { not approve of that } \\
\text { I'm cc-ing Peter to keep } \\
\text { him in the loop }\end{array}$ & \\
\hline
\end{tabular}




\begin{tabular}{|l|l|l|}
\hline Simplification & $\begin{array}{l}\text { will check and get back to } \\
\text { you asap } \\
\text { Fine with } 2.30\end{array}$ & \\
\hline Abbreviations & & Rgds, Richard \\
\hline New meanings & & $\begin{array}{l}\text { will email the copies and spreadsheet } \\
\text { first thing tomorrow morning. } \\
\text { please remember to cc Martha. }\end{array}$ \\
\hline
\end{tabular}

(From Gimenez 2005, 2006)

\section{Latest developments in EMC}

15 Advances in technology and increasing workplace exigencies meant that people have had to come up with new ways of responding to communication demands. One example that has started to attract significant theoretical and research attention is what we call 'multicommunication'.

The workplace has become a complex communicative space where the demand for 'doing more in less time' seems to be the prevailing norm. To respond to such a demand, business people are resorting to what recent research has identified as multicommunication, that is, holding multiple 'conversations' at the same time (Gimenez 2010; Stephens \& Davis 2009; Turner and Reinsch, 2007, 2010). Turner and Reinsch, for example, studied twenty experienced multicommunicators at a large, hightech organisation and discovered that to cope with new communication demands multicommunicators cycled among "several chat conversations while opening an email and responding to his or her boss on a pager" (2007: 37). In a similar vein, Stephens and Davis (2009) examined multitasking in technology-infused organisations and found that at meetings people engage in multiple tasks which are not always meeting-related. Figure 1 shows a screenshot of the PC of one multicommunicator at work. As can be seen, they were not only communicating by email and on a chat facility, but also working on a presentation and a Word document, all at the same time. 
Figure. 1. Screenshot of the PC of a multicommunicator at work

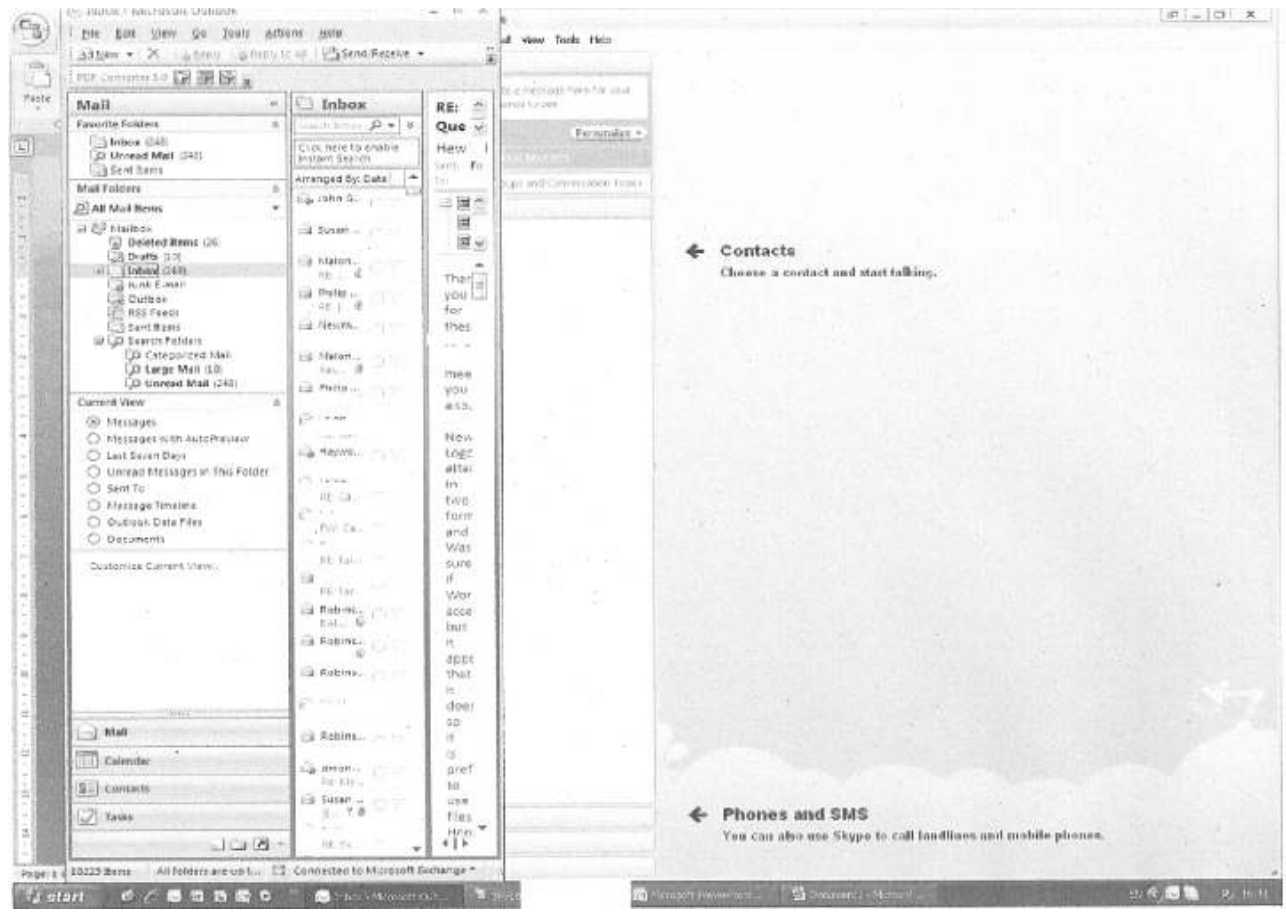

One of the most significant results of studies in multicommunication relates to how multicommunicators package different media to do more in less time. The most typical combination appears to be email, mobile phone and instant message (IM); followed by email and IM; and email and telephone. Most multi-communicators prefer packaging either two written - or what is perceived as 'written' - media (e.g., email and IM), or a written and a spoken media (email + telephone/mobile phone, IM + telephone) together, especially for messages dealing with the same or a similar topic.

Another recent significant development in EMC is what has been termed Enterprise Social Networking (ESN) such as YouTube, Twitter and Facebook which have become common features on the websites of many institutions and corporations. This is a very recent development and there are still many questions that need further research attention. It will be interesting to know, for example, why institutions and corporations have adopted ESN so readily. Social media marketing and increased on-line presence seem to be the most obvious reasons. But is this all there is to social networking for business purposes? On the client and customer side, apart from being kept informed about products, services and Public Relations efforts, is there anything else that encourages customers to follow a company's postings on Twitter or Facebook?

19 A recent exploratory study (Gimenez 2012) that used textual analysis (websites and postings), interviews (with corporate communication officers and customers) and a number of multimodal artefacts (websites, podcasts and video clips) shows a number of other less obvious reasons why a number of corporations in the United Kingdom and some of their customers have turned to ESN to interact.

Its preliminary results show that beyond the most obvious purposes, ESN in corporate communication is used by corporations and their customers to:

- help to put a human face on businesses;

- create awareness of (new) products and services;

- recruit new members of staff (instead of only using business-oriented networking sites); 
- engage followers for product development (e.g., prosuming);

- interact with like-minded people in a particular industry; and

- ask for advice or referrals from other customers.

21 This is another exciting development in EMC that has started to play a role in professional communication and that needs to be examined more closely.

\section{Future trends in EMC}

There are a number of topics and activities in electronically-mediated communication which will occupy our research time and interest. In terms of topics, some of the emerging themes and questions that have started to attract considerable research attention are:

EMC in the workplace: The nature and dynamics of EMC in the new workplace where doing more in less time is becoming the prevailing norm. Some of the questions that need further investigation include: how it is done, how it happens, and what implications it all has for research and teaching purposes;

Skills for the workplace: The skills and strategies needed to operate effectively in workplace EMC. Some questions here would be: what these are, how to best help students and train people in companies to develop these skills and strategies in an effective way, how these strategies are valued in the workplace, and whether they form part of performance assessment;

Enterprise Social Networking (ESN): The role of ESN in mediating the relationship between institutions and corporations and their clients and customers. The central question in relation to this is how we can bring customers and clients into the centre of our research agenda.

There are also a number of activities and needs that the topics mentioned above will create:

New methods of research: There is scope for applying more multi-faced research methods (e.g., ethnography) to be able to capture the wide-ranging nature of EMC;

Research and practice: Creating a closer link between research and practice so that we can strike a better balance between research-informed practice and practice-led research;

Producers and consumers: Using research and practice to provide more opportunities for users/consumers of products and services to talk about their experiences in communicating with their products and services providers in a mediated way.

These topics and activities will allow us to:

- examine the language and discourses that give substance to electronically mediated communication in the workplace;

- make stronger links between the theoretical developments in the field, its research findings and new didactic applications;

- bring the culture of the context where EMC takes place more to the forefront, showing, for instance, how power and gender interact with communication aims and agendas; and

- continue exploring new technological advances so that technology becomes a means to our communication purposes rather than their aim. 


\section{Conclusion}

This paper has revisited the main contributions in the field of EMC over the past two decades. In particular, it focused on how EMC interacts with context of use, the identity communicators and the culture of the workplace. It also examined emerging tendencies in EMC such as multicommunication and Enterprise Social Networking (ESN). Against this background it has delineated an agenda for research topics and activities that need further attention and investigation.

There is still a great deal of work that we need to do in the field of EMC. There is, for instance, a need for more multifaceted research methods that would allow us to better capture the dynamic nature of EMC. By the same token, the over-emphasis on the production end of EMC needs to be counterbalanced with more attention to how EMC is received and consumed. To that effect, we need to bring consumers and customers to the centre of our research and pedagogic efforts. These new avenues of enquiry present exciting challenges lying ahead of us which I hope will find a way into the activities of professional associations like Groupe d'Étude et de Recherche en Anglais de Spécialité (GERAS) and its professional meetings.

This paper has been written on the basis of the plenary delivered at the 33rd Colloque du GERAS, Université Stendhal - Grenoble 3. I am grateful to Shaeda Isani and Elisabeth Lavault-Olléon for their invitation and to Guadalupe Aguado, Alejandro Cuardo Fuentes and Gilberto Diaz-Santos for their kind comments. I am also thankful to the participants in my various projects; without their time and expertise none of this would have ever been possible.

\section{BIBLIOGRAPHY}

Akar, Didar. 2002. "The macro contextual factors shaping business discourse: The Turkish case". International Review of Applied Linguistics in Language Teaching 40, 305-322.

Daft, Richard L. and Robert H. Lengel. 1986. "Organizational information requirements, media richness, and structural determinants”. Management Science 32, 554-571.

Gimenez, Julio. 2000. "Business e-mail communication: some emerging tendencies in register". English for Specific Purposes 19, 237-251.

Gimenez, Julio. 2002. "New media and conflicting realities in multinational corporate communication: A case study". International Review of Applied Linguistics in Language Teaching 40, 323-343.

Gimenez, Julio. 2005. “Unpacking business emails: Message embeddedness in international business email communication”. In Gotti M. and P. Gillaerts (eds.), Genre Variation in Business Letters 24. Bern: Peter Lang, 235-255

Gimenez, Julio. 2006. "Dynamic evolution: An exploration of textual changes in business emails". In Camiciotti G. Del Lungo, M. Dossena and B. Crawford (eds.), Variation in Business and Economics Discourse. Rome: Officina Edizioni, 69-83. 
Gimenez, Julio. 2010. "Mediated multicommunication: Redefining the notion of 'effective communication' in business settings". Paper presented at the 10th ABC Europe Conference, 22nd May 2010.

Gimenez, Julio. 2012. “'Follow us': An exploration of the role of enterprise social networking (ESN) in corporate communication". Paper presented at the 11th ABC Europe Conference, 1 June 2012.

Jensen, Astrid. 2009. "Discourse strategies in professional e-mail negotiation: a case study". English for Specific Purposes 28, 4-18.

Lengel, Robert H. and Richard L. Daft. 1988. "The selection of communication media as an executive skill”. The Academy of Management Review 2, 225-232.

Markus, M. Lynne. 1994. "Electronic mail as the medium of managerial choice". Organization Science 5, 502-527.

Nickerson, Catherine. 1999. "The use of English in electronic mail in a multinational corporation”. In Bargiela-Chiappini F. and C. Nickerson (eds.), Writing Business: Genres, Media and Discourses. Harlow, Essex: Longman, 35-56.

Poncini, Gina. 2002. "Investigating discourse at business meetings with multicultural participation”. International Review of Applied Linguistics in Language Teaching 40, 345-373.

Stephens, Keri K. and Jennifer Davis. 2009. “The social influences on electronic multitasking in organizational meetings". Management Communication Quarterly 23, 63-83.

Turner, Jeanine Warisse and N. Lamar Reinsch. 2007. "The business communicator as presence allocator: Multi-communicating, equivocality, and status at work". Journal of Business Communication 44, 36-58.

Turner, Jeanine Warisse and N. Lamar Reinsch. 2010. "Successful and unsuccessful multicommunication episodes: Engaging in dialogue or juggling messages?”. Information Systems Frontier 12, 277-285.

\section{ABSTRACTS}

This paper revisits the contributions that the field of electronically-mediated communication (EMC) has made to our understanding of the nature and purposes of communication in professional contexts. It examines theoretical and pedagogic affordances created by recent technological developments. The paper closes by outlining an agenda for future research in the field of EMC. It delineates how the topics and activities in the agenda can be linked to the four epistemological axes discussed at the GERAS 33rd conference: language and discourse, didactics, culture and technology.

Cet article fait l'état des lieux des apports que l'étude du domaine de la communication véhiculée par l'électronique a eu en ce qui concerne notre compréhension de la nature et des objectifs de la communication en contexte professionnel. Il analyse les possibilités créées par les avancées technologiques récentes. L'article clôt sur un programme de recherches futures dans le domaine la communication véhiculée par l'électronique. Il met en avant la façon dont les thèmes ainsi que les activités dans ce programme peuvent être reliés aux quatre axes épistémologiques discutés lors du $33^{\mathrm{e}}$ colloque du GERAS : langue et discours, didactique, culture et technologie. 


\section{INDEX}

Mots-clés: communication multimodale, courrier électronique, langue et discours, pratique pédagogique

Keywords: electronically-mediated communication, language and discourse, multimodal communication, pedagogic practice

\section{AUTHOR}

\section{JULIO GIMENEZ}

Julio Gimenez is a Lecturer in English language and academic literacies at the University of Nottingham, United Kingdom. His main research interests are in the areas of workplace communication and narrative discourse analysis. His work has been published in international journals such as English for Specific Purposes, International Review of Applied Linguistics and Journal of English for Academic Purposes, as well as in various edited collections.

julio.gimenez@nottingham.ac.uk 